\section{Multicentric reticulohistiocyto- sis: an example of the value of skin biopsy in joint disease}

\author{
Ruth Smith, ${ }^{1}$ Chris Stonard,2 \\ Rengi Mathew ${ }^{3}$
}

'Department of Rheumatology, Sheffield Teaching Hospitals; ${ }^{2}$ Department of Histopathology, Chesterfield Royal Hospital; ${ }^{3}$ Department of Rheumatology, Chesterfield Royal Hospital, UK

\section{Abstract}

We describe a case of multicentric reticulohistiocytosis. It is a rare condition but one which causes significant morbidity to skin and joints. There is no consensus on treatment, but here we report a good response to infliximab. We also use the case to emphasise the value of skin biopsy in diagnosing rheumatological conditions.

\section{Introduction}

Multicentric reticulohistiocytosis is a rare condition of unknown aetiology. About two hundred cases have been reported in the literature. ${ }^{1}$ It is a systemic condition characterised by papulonodular cutaneous lesions and a polyarthritis which can lead to leonine facies and an incapacitating arthritis. ${ }^{2}$ It has associations with autoimmune conditions, hyperlipidaemia, and malignancy. Co-existent autoimmune diseases such as diabetes mellitus, hypothyroidism, Sjogren's syndrome, primary biliary cirrhosis, systemic sclerosis and myopathy have been identified in $6-17 \%$ of cases, and an association with hyperlipidaemia has been described in $30-58 \%$. Malignancy has been reported in $15-28 \%$ of cases. There is no tendency towards one type of cancer; instead associations have been made with carcinoma of the breast, cervix, ovary, stomach, colon, lung and bronchus, mesothelioma, melanoma, lymphoma, leukaemia and sarcoma. ${ }^{3}$ The cutaneous lesions of multicentric reticulohistiocytosis can precede or be present with a malignant process, and their regression has been reported following treatment for malignancy. ${ }^{4}$

Given the rarity of the condition there are no trials to inform treatment decisions. Recommendations are based on isolated case reports and success has been described with steroids, disease modifying antirheumatic drugs and biologics. Etanercept has been used as monotherapy and in combination..$^{5,6}$ and infliximab has previously been shown to improve skin lesions but to have minimal effect on joints. ${ }^{7}$ In our patient, infliximab produced an excellent response in both skin and joints.

Biopsy of the cutaneous lesions shows a virtually pathognomonic cytomorphology. This includes large histiocytes and multinucleate giant cells with eosinophilic ground glass cytoplasm. ${ }^{8}$ Here we use our case to emphasise the value of skin biopsy in diagnosing a number of rheumatological conditions.

\section{Case Report}

Our patient is a 62 year old lady who initially presented with pain and swelling in the small joints of her hands. Synovitis was detected on examination, but rheumatoid factor was negative. A clinical diagnosis of rheumatoid arthritis was made and a good response to treatment with steroids was observed. Our patient continued on low dose steroids, and was taking prednisolone $3 \mathrm{mg}$ daily when she represented ten years later in 1995 with a ten week history of nodular erythematous lesions on her hands, forearms, trunk and thighs (Figure 1). She had restricted wrist movements and synovitis in her metatarsophalangeal joints. C-reactive protein was normal, and rheumatoid factor and anti-cyclic citrullinated peptide antibodies were negative. X-rays of her hands and feet showed an erosive arthropathy.

Skin biopsy was consistent with multicentric reticulohistiocytosis (Figure 2). It showed a normal epidermis with a narrow Grenz zone above an ill-defined deposit (diffuse rather than nodular dermatitis) of large cells of histiocytic cytomorphology. These included occasional multinucleate forms and had an abundance of eosinophilic cytoplasm with fine granularity, resulting in a classical ground glass appearance. Monoclonal antibody staining was positive for the histiocytic marker CD68. Once the diagnosis of multicentric reticulohistiocytosis had been confirmed, our patient underwent screening for malignancy. All investigations were negative.

Treatment was commenced with prednisolone $30 \mathrm{mg}$ daily and methotrexate $5 \mathrm{mg}$ weekly. The steroids were reduced but attempts to increase the methotrexate dose were limited by problems with gastrointestinal side effects. The highest dose reached was $12.5 \mathrm{mg}$ weekly, but in the main our patient tolerated between $2.5 \mathrm{mg}$ and $5 \mathrm{mg}$ weekly. The combination improved the joints more than the skin, but after a number of years disease control was lost. Ten pulses of intravenous 750 mg cyclophosphomide were given. Azathioprine was then initiated, and main tained at a dose of $50 \mathrm{mg}$ twice daily. This
Correspondence: Ruth Smith, Department of Rheumatology, Royal Hallamshire Hospital, Glossop Road, Sheffield, S102JF, UK.

Tel.: +44114271 1947 - Fax: +44114271 1844.

E-mail: ruthsmith4@nhs.net

Key words: Multicentric reticulohistiocytosis; arthritis; infliximab; skin biopsy.

Contributions: RS, manuscript writing; CS, manuscript writing; RM, manuscript reviewing.

Conflict of interest: the authors declare no potential conflict of interest.

Received for publication: 10 February 2015.

Revision received: 16 March 2015.

Accepted for publication: 17 March 2015.

This work is licensed under a Creative Commons Attribution NonCommercial 3.0 License (CC BYNC 3.0).

(C) Copyright R. Smith et al., 2015

Licensee PAGEPress, Italy

Rheumatology Reports 2015; 7:5832

doi:10.4081/rr.2015.5832

improved the skin, but the joints remained symptomatic. After twelve months, both skin and joints deteriorated and azathioprine was replaced by cyclosporine $100 \mathrm{mg}$ twice daily. This produced a limited response and was discontinued at the patient's request. A subsequent relapse led to initiation of mycophenolate $500 \mathrm{mg}$ twice daily, but gastrointestinal upset prevented dose increases. Infliximab was added in at a dose of $200 \mathrm{mg}$ every seven weeks, and a dramatic and sustained response in both skin and joints was seen.

However, in spite of good control of the skin lesions and joint disease, our patient experienced two episodes of shortness of breath which were attributed to the systemic manifestations of multicentric reticulohistiocytosis. In 2008, a high resolution computerised tomography scan showed bi-basal bronchiectasis and widespread areas of ground glass opacification suggestive of non-specific interstitial pneumonia. The consensus was that this was part of multicentric reticulohistiocytosis rather than an extra-articular manifestation of rheumatoid arthritis. Our patient responded well to treatment with prednisolone $30 \mathrm{mg}$ daily, subsequently weaned by $5 \mathrm{mg}$ per week. In 2011 , an echocardiogram showed aortic regurgitation and a mild pericardial effusion, again thought to be related to multicentric reticulohistiocytosis. The effusion regressed with prednisolone $15 \mathrm{mg}$ daily, reduced by $5 \mathrm{mg}$ every two weeks. At review in 2012, the patient's symptoms remained suppressed on infliximab, mycophenolate $500 \mathrm{mg}$ twice daily and prednisolone $5 \mathrm{mg}$ once daily. 


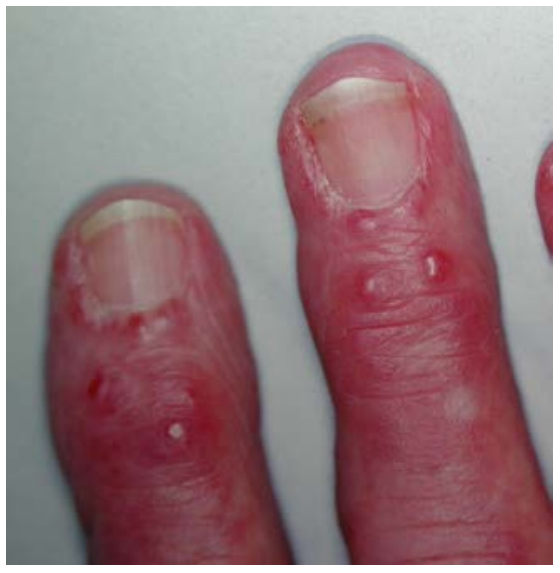

Figure 1. Photograph showing papules in the periungual region producing a coral bead appearance.

\section{Discussion}

In this case it was the histological examination of the skin lesions, which in multicentric reticulohistiocytosis have a very characteristic cell morphology, which informed the diagnosis. The co-existence of skin and joint disease is not uncommon. The skin is the easiest organ to biopsy, and the following may be sited as further instances in which a skin biopsy might facilitate the diagnosis of a rheumatological problem: i) psoriasis; ii) tophi in gout; iii) skin nodules in rheumatoid arthritis and rheumatic fever; iv) erythema chronicum migrans of early and acrodermatitis chronica atophicans of late Lyme disease; v) vasculitis, both leucocytoclastic (as in Henoch-Schönlein purpura) and granulomatous (as in granulomatosis with polyangitis); vi) sarcoidosis; vii) Kaposi's sarcoma in AIDS.

\section{Conclusions}

In most of these instances the histological diagnosis depends on the pattern analysis of inflammation, ${ }^{9}$ or in the case of early Kaposi's sarcoma, malignancy. Multicentric reticulohistiocytosis is unusual in that cell morphology is virtually pathognomonic of the condition and more valuable than pattern analysis. The diagnosis could be made on a biopsy of the synovium, as the typical cells are present there. However, a skin biopsy has the advantage of ease of execution, safety, and for interpretation a better defined pattern of deposition of the atypical cells.

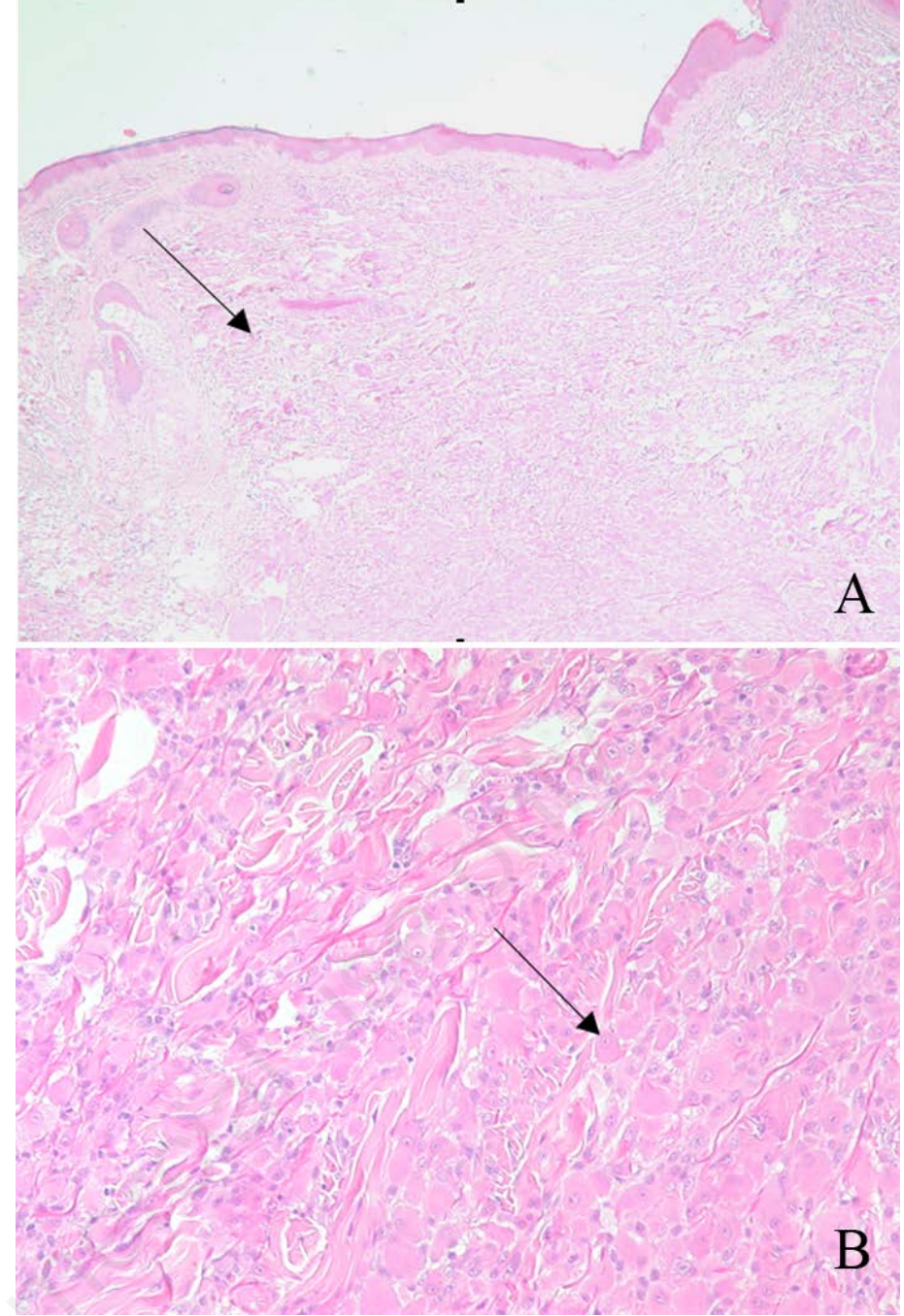

Figure 2. A) Skin biopsy showing a diffuse dermal infiltrate of large cells extending between collagen bundles. Haematoxylin \& Eosin stain photographed at $40 \times$ magnification; B) the large cells are mainly mononuclear with plentiful eosinophilic ground glass texture cytoplasm. Haematoxylin \& Eosin stain photographed at $200 \times$ magnification.

\section{References}

1. Santilli D, Lo Monaco A, Cavazzini PL, Trotta F. Multicentric reticulohistiocytosis: a rare cause of erosive arthropathy of the distal interphalangeal finger joints. Ann Rheum Dis 2002:61:485-7.

2. Luz FB, Gaspar NK, Gaspar AP, et al. Multicentric reticulohistiocytosis: a proliferation of macrophages with tropism for skin and joints, part 1. Skinmed 2007:6: 172-8.

3. Gorman JD, Danning C, Schumacher HR, et al. Multicentric reticulohistiocytosis. Case report with immunohistochemical analysis and literature review. Arthritis Rheum 2000:43:930-8.

4. West KL, Sporn T, Puri PK. Multicentric reticulohistiocytosis. A unique case with pulmonary fibrosis. Arch Dermatol
2012:148:228-32.

5. Kovach BT, Calamia KT, Walsh JS, et al. Treatment of reticulohistiocytosis with etanercept. Arch Dermatol 2004:140:91921.

6. Rodriguez-Cerdeira C, Sanchez-Blanco B, San Millan B, Vilata, JJ. Multicentric reticulohistiocytosis treated successfully with etanercept. Open Dermatol J 2008:2:44-7.

7. Sellam J, Job Deslandre C, Dubreuil F, et al. Refractory multicentric reticulohistiocytosis treated by infliximab: two cases. Clin Exp Rheumatol 2005:23:97-9.

8. Sroa N, Zirwas MJ, Bechtel M. Multicentric reticulohistiocytosis: a case report and review of the literature. Cutis 2010:85:153-5.

9. Ackerman A. Histologic diagnosis of inflammatory skin diseases: a method by pattern analysis. Philadelphia: Lea \& Febiger; 1978. 